Proceedings of the 2006 Winter Simulation Conference

L. F. Perrone, F. P. Wieland, J. Liu, B. G. Lawson, D. M. Nicol, and R. M. Fujimoto, eds.

\title{
OBSERVATIONS ON MATERIAL FLOW IN SUPPLY CHAINS
}

\author{
S. T. Enns \\ Dept. of Mechanical and Manufacturing Engineering \\ University of Calgary \\ Calgary, AB., T2N-1N4, CANADA
}

\author{
Pattita Suwanruji \\ Bantrel Company \\ $700-6^{\text {th }}$ Ave. SW \\ Calgary, AB., T2P-08T, CANADA
}

\begin{abstract}
This paper summarizes one group of recent simulation studies comparing replenishment strategies. Time-phased planning, implemented using DRP and MRP logic, continuous-review reorder point (ROP) and single-card Kanban (KBN) systems are considered. These differ in terms of decision-making information, logic and integration requirements. Experimental results have been statistically analyzed and explained using simple stochastic models. Steps have also been taken to evaluate which strategies are most suitable under various demand patterns, levels of uncertainty and capacity constraints. Results show that DRP/MRP is superior under time-varying demand, regardless of whether or not capacity constraints are present. With no capacity constraints and level demand, ROP is superior to $\mathrm{KBN}$, in part because it considers backorder information. With capacity constraints behavior is complicated by queuing effects. Under level demand, KBN may slightly outperform ROP, given assumptions of equal lot sizes, order placement delays and transportation times.
\end{abstract}

\section{INTRODUCTION}

The purpose of this paper is to summarize some of the recent findings of a research stream being pursued by the authors. The results relate to studies performed using a single test bed and methodology. This facilitates making comparisons across scenarios and gaining more general insights. The lack of consistency in methodologies and measures is one reason there is still ambiguity in the research literature regarding replenishment in supply chains.

One of the main objectives of this research is to investigate differences in performance using alternative replenishment strategies. This includes determining under what conditions one strategy is preferable to others. The three basic strategies considered are those most commonly encountered in practice, namely the time-phased, reorder point and Kanban strategies. Comparing these under different supply chain assumptions, such as configuration and demand pattern, is important. In supply chains without ca- pacity constraints, Distribution Requirements Planning (DRP) logic is used to implement time-phased replenishment. With capacity constraints, Material Requirements Planning (MRP) logic is implemented. In both cases these are assumed to be time-bucketed systems driven by a master schedule, which in turn relies on forecast information. This forecast information is assumed to be unbiased throughout the demand cycle. Regeneration of plans occurs on a periodic basis. The reorder point (ROP) system considered uses continuous review. The Kanban (KBN) implementation is based on single-card logic. In all cases, it is assumed that order placement is instantaneous. This biases the Kanban system slightly toward greater responsiveness since in practice the circulation of cards used in placing orders usually involves a significant delay.

The experimental methodology is one of modeling supply chain networks using discrete-event simulation. A simple, flexible and user-friendly test bed designed for this purpose is discussed in Enns and Suwanruji (2003). Experimentation is performed using designed experiments with factors relating to the supply chain environment, such as demand uncertainty, or to operating variables under management control, such as lot sizes. Performance is measured in terms of inventory counts for all parts in the supply chain and delivery mean tardiness for customer deliveries. Tradeoff curves between these two measures are generated, as shown in Figure 1. This is done by varying the planned lead times, order points and number of cards for the time-phased (DRP/MRP), reorder point and Kanban replenishment strategies, respectively. Results are analyzed by determining the area under the trade-off curves and then statistically comparing them. This allows factor effects and interactions to be determined. As well, the performance across different replenishment strategies can be statistically compared. A curve closer to the origin results in a smaller area and better performance. In other words, less inventory is required for the same delivery performance (or vice versa) as the curve shifts closer to the origin. This methodology is explained further in Suwanruji and Enns (2004). 
The next section examines performance without capacity constraints. In Section 3 the effect of queues resulting from capacity constraints is considered. Finally Section 4 discusses comparisons with and without capacity constraints.

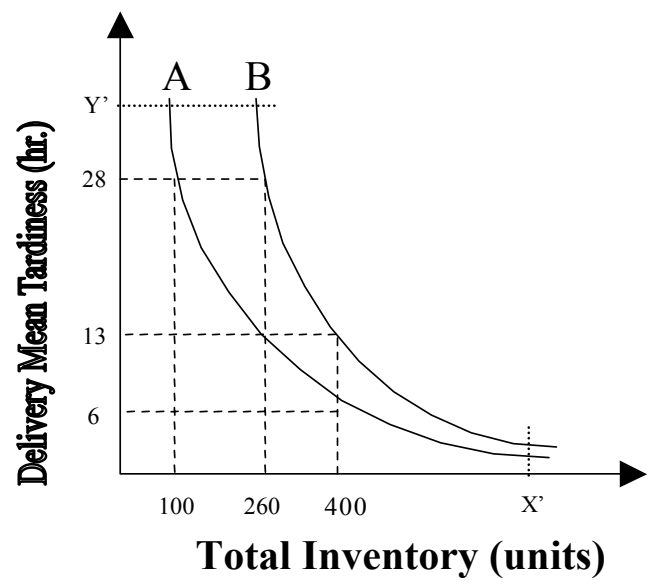

Figure 1. Inventory-Mean Tardiness Trade-Off Curves

\section{PERFORMANCE EVALUATION WITHOUT CAPACITY CONSTRAINTS}

An initial study of a simple distribution system without capacity constraints was considered. The configuration is shown in Figure 2. A full factorial experimental design was created in which two levels of demand patterns (DP), two levels of lot sizes (LS), two levels of demand uncertainty (DU) and two levels of transit time uncertainty (TU) were used. For the demand pattern, the first level assumed a stationary demand pattern through time and the second level assumed seasonal demand with a one-year cycle. The two levels for the other factors represented low and high settings for the variables controlling lot sizes or uncertainties. Details of the model and experimental design can be found in Suwanruji and Enns (2006a).

Extensive experimentation resulted in tradeoff curve areas for all combinations of factor settings. A leastsquares regression model was then developed using the area under the curves as the response. Independent variables included the factor settings and interactions between these settings. Table 1 summarizes the main effects of moving from a low $(-1)$ to high $(+1)$ setting. For current purposes only the relative size of effects, not the actual response values, are of interest. A positive value for the effect indicates performance is better at the low level since the area under the curve is lower.

The results in Table 1 show that DRP is insensitive to the demand pattern (DP) whereas ROP and KBN performance deteriorates as demand becomes seasonal. This suggests that time-phased planning is particularly beneficial if demand is seasonal and if this seasonality can be accu- rately forecasted. The sensitivity to demand seasonality is also less for ROP than for KBN. This is at least partially due to the ability of ROP to consider backorders at the time of order placement, something KBN does not facilitate (Suwanruji and Enns, 2002).

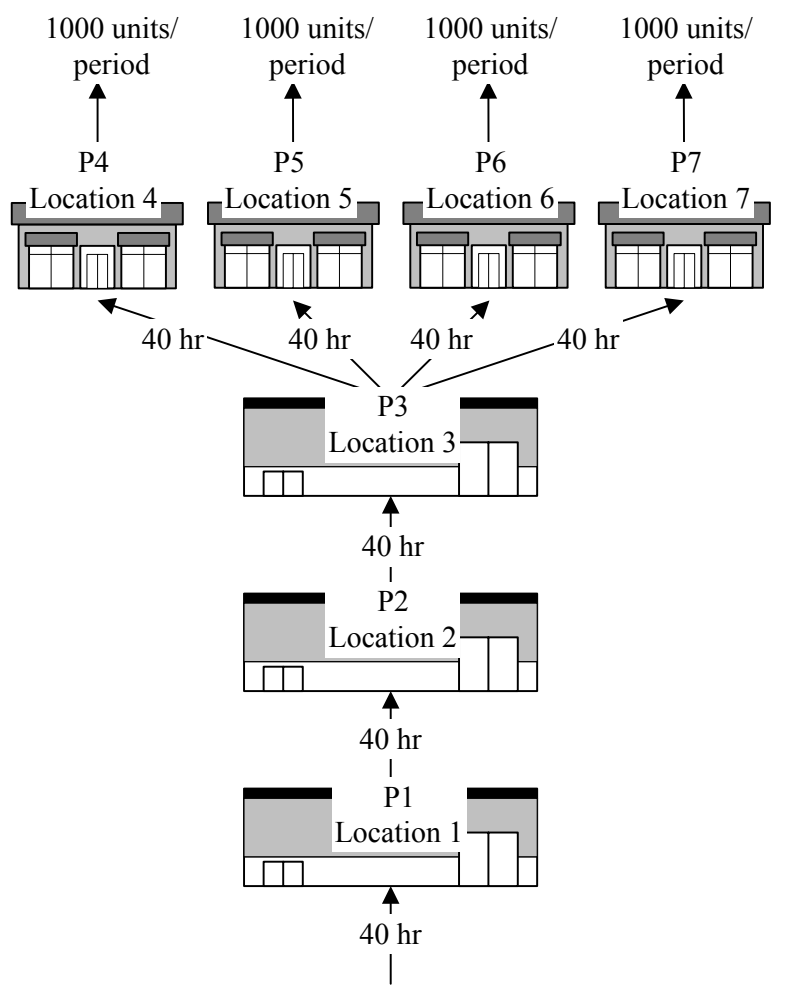

Figure 2. Configuration of Distribution System

\begin{tabular}{|c|c|c|c|}
\hline & \multicolumn{2}{|c|}{ Table 1. Main effects } & \\
\hline & DRP & ROP & KBN \\
\hline DP & - & 9787 & 21913 \\
\hline LS & 1371 & 2006 & 7198 \\
\hline DU & 5208 & 3118 & 2407 \\
\hline TU & 3523 & 2983 & 3942 \\
\hline
\end{tabular}

The lot size (LS) results show that small lot sizes are better for all replenishment strategies. However, this result does not consider order or delivery costs. In most cases these are significant and relationships such as the Economic Order Quantity (EOQ) can be used to determine reasonable order quantities. The demand uncertainty (DU) and transit time (TU) uncertainty results indicate that increasing levels of uncertainty cause performance to deteriorate. This result is consistent with expectations.

Extensive comparisons can be made between replenishment strategies. Table 2 summarizes results for comparisons across all other factor settings except the demand pattern (DP). The demand patterns are separated out in this table since they have a dominant effect and obscure identification of other significant effects. The values in 


\section{Enns and Suwanruji}

Table 2 indicate pair-wise 95\% confidence intervals, adjusted using the Bonferroni technique for multiple comparisons. An interval that contains zero indicates no statistical significance whereas an interval that contains only positive values indicates the second strategy in the pair is superior. For example, the confidence interval for the mean difference when areas under the DRP response curves are subtracted from those under the Kanban curves (KBN-DRP) is $(7304,8383)$ under level demand. Since the area under the curves is greater for $\mathrm{KBN}$, performance is worse.

Table 2. Confidence Intervals

\begin{tabular}{|c|c|c|c|}
\cline { 2 - 4 } \multicolumn{1}{c|}{} & ROP-DRP & KBN-DRP & KBN-ROP \\
\hline Level & $(-831$, & $(7304$, & $(7596$, \\
Demand & $247)$ & $8383)$ & $8675)$ \\
\hline Seasonal & $(9174$, & $(29401$, & $(19851$, \\
Demand & $9927)$ & $30155)$ & $20605)$ \\
\hline
\end{tabular}

The results in Table 2 show that under level demand DRP and ROP perform about the same, while KBN performance is not quite as good. However, under seasonal demand DRP performs better by far, followed by ROP and KBN. These observations are consistent with Table 1. The forecast information used by DRP, assumed to be unbiased in this research, is particularly beneficial under seasonal demand since it allows proactive replenishment adjustments. ROP and KBN both adjust to demand changes on a reactive basis, although backorder information helps ROP to a limited extent.

These results provide only a very basic understanding but one that is essential to evaluating replenishment strategies. In addition there are various interaction effects that are significant. These are beyond the scope of this paper but are considered in Suwanruji and Enns (2006a).

\section{PERFORMANCE EVALUATION WITH CAPACITY CONSTRAINTS}

The introduction of capacity-constrained resources, such as manufacturing machines, results in quite different behavior. This is largely due to queuing effects. Batch, or lot, flowtimes through capacity constrained machines can be modeled using queuing approximations. The following is a common $\mathrm{GI} / \mathrm{G} / 1$ approximation used to model flowtimes through a single capacity-constrained resource (Whitt, 1983).

$$
W=W_{q}+\bar{x}=\bar{x} \frac{\left(c_{a}^{2}+c_{s}^{2}\right)}{2} \frac{\rho}{1-\rho}+\bar{x}
$$

where $W_{q}$ is the weighted mean queue time, $\bar{x}$ is the weighted mean lot service time, $c_{a}$ is the coefficient of variation for lot interarrival times, $c_{s}$ is the coefficient of variation for lot service times and $\rho$ is the utilization rate.

When lots of different part types are processed at the machine, additional equations for $\bar{x}, c_{s}$ and $\rho$ are required

(Enns and Choi, 2002).

$$
\bar{x}=\frac{\sum_{j=1}^{n} \frac{D_{j}}{Q_{j}}\left[\tau_{j}+\frac{Q_{j}}{P_{j}}\right]}{\sum_{j=1}^{n} \frac{D_{j}}{Q_{j}}}
$$

where $j$ is the product type index, $D_{j}$ is the demand rate, $Q_{j}$ is the product type lot size, $P_{j}$ is the part processing rate, and $\tau_{i, j}$ is the lot setup time.

$$
\begin{gathered}
\rho=\sum_{j=1}^{n}\left[\frac{D_{j}}{Q_{j}}\left(\tau_{j}+\frac{Q_{j}}{P_{j}}\right)\right] \\
c_{s}^{2}=\frac{\sum_{j=1}^{n} \frac{D_{j}}{Q_{j}}\left[\tau_{j}+\frac{Q_{j}}{P_{j}}\right]^{2}\left(\sum_{j=1}^{n} \frac{D_{j}}{Q_{j}}\right)^{-1}}{\bar{x}^{2}}-1
\end{gathered}
$$

It is obvious that increasing variability of lot interarrival times increases flowtimes, since this causes $c_{a}$ to increase. When flowtimes increase either inventory levels will increase, as stated by Little's Law (Little, 1961), or delivery performance will deteriorate. Therefore uncertainty negatively affects performance, just as in the case of unconstrained systems. It is also obvious that as throughput increases, the machine utilization will increase and this will also cause average flowtimes to increase.

The effect of lot sizes in capacity-constrained systems is harder to evaluate but more interesting. Assuming each lot of parts requires a setup time, the relationship between lot sizes and flowtimes is convex. Given the above relationships, this can be proved for the single product case and demonstrated for multiple product cases (Enns and $\mathrm{Zhu}, 2005)$. Lot sizes that minimize the estimated average lot flowtimes can be easily obtained using non-linear optimization. However, a significant problem in lot size selection is that Equation (1) assumes lot interarrival times are independent. This is not usually true in either supply, manufacturing or distribution systems. Under most conditions the interarrival times are auto-correlated and the prediction of flowtimes using Equation (1) is poor. Enns and Li (2004) suggest a dynamic feedback approach that corrects for auto-correlation effects.

Lot size optimization using queuing analysis results in Fixed Order Quantity (FOQ) lot sizes. This lot-sizing policy can be applied in the same manner to DRP/MRP, ROP and $\mathrm{KBN}$. It is therefore an appropriate lot-sizing policy to 
be used when comparing different replenishment strategies since comparisons are kept fair. However, in the case of time-phased systems there are many other lot-sizing policies that can be implemented. Two common ones in practise are Lot-for-lot (LFL) and Period-Order-Quantity (POQ), both of which are often recommended because they reduce remnant inventory. The weakness of these policies is that lot sizes are propagated through levels of planning without consideration of capacity constraints. Performance can be quite poor as a result. A recent study using MRP has demonstrated that FOQ lot sizes based on flowtime minimization result in much better performance than LFL or POQ (Enns and Suwanruji, 2005). These results are consistent with the idea that lot sizes should be based on bottleneck resources (Goldratt, 1984).

In addition, there are more likely to be coordination issues in capacity-constrained supply chains, especially as it relates to lots of parts going into assembly operations. Preliminary investigations have shown that the ability to coordinate parts depends on the replenishment strategy being used. Time-phased replenishment generally results in less delay waiting for the arrival of all component part lots going into parent part assemblies.

\section{COMPARISONS WITH AND WITHOUT CAPACITY CONSTRAINTS}

A second study can be used to illustrate and compare differences in performance between supply chains with and without capacity constraints. The scenario used for experimentation is shown in Figure 3. This scenario includes locations, L3 to L6, that can be treated as capacity constrained resources. As well, there are assembly operations involved, as indicated by the Bill-of-Materials (BOM) involved in creating the final products shown in the Bill-ofDistribution (BOD). Further details of the scenario are given in Suwanruji and Enns (2006b).

The three replenishment strategies previously identified were again used in an experimental design. However, the time-phased strategy assumed use of MRP logic at the capacity constraints. The other two factors were the capacity constraint and the demand pattern, both run at two levels. For the capacity constraint, the first level indicates there are no constraints or queuing effects, while the second level indicates there are setup and processing times that constrain flow at capacitated machines. For the demand pattern, the first level assumes a stationary demand pattern and the second level assumes seasonal demand. The simulation test bed identified previously was again used to run the experimental design. As well, inventory counts and delivery tardiness measures were used to create tradeoff curves, with the area under these curves was treated as the response.

Pair-wise Bonferroni 95\% confidence intervals were again created to compare the replenishment systems.
These are shown in Table 4. For this supply chain scenario it can be observed that, with no capacity constraints, ROP performed slightly better than DRP/MRP. This was followed by KBN. Under seasonal demand DRP was the best, followed by ROP and KBN. This is consistent with the findings in Section 2. However, with capacity constraints and level demand it can be observed that KBN performed the best, followed by DRP/MRP and ROP. With capacity constraints and seasonal demand DRP/MRP performed best, followed by ROP and KBN. These results are also summarized in Figure 4, where the left to right order of strategies in each corner of the matrix indicates increasing area (decreasing performance).

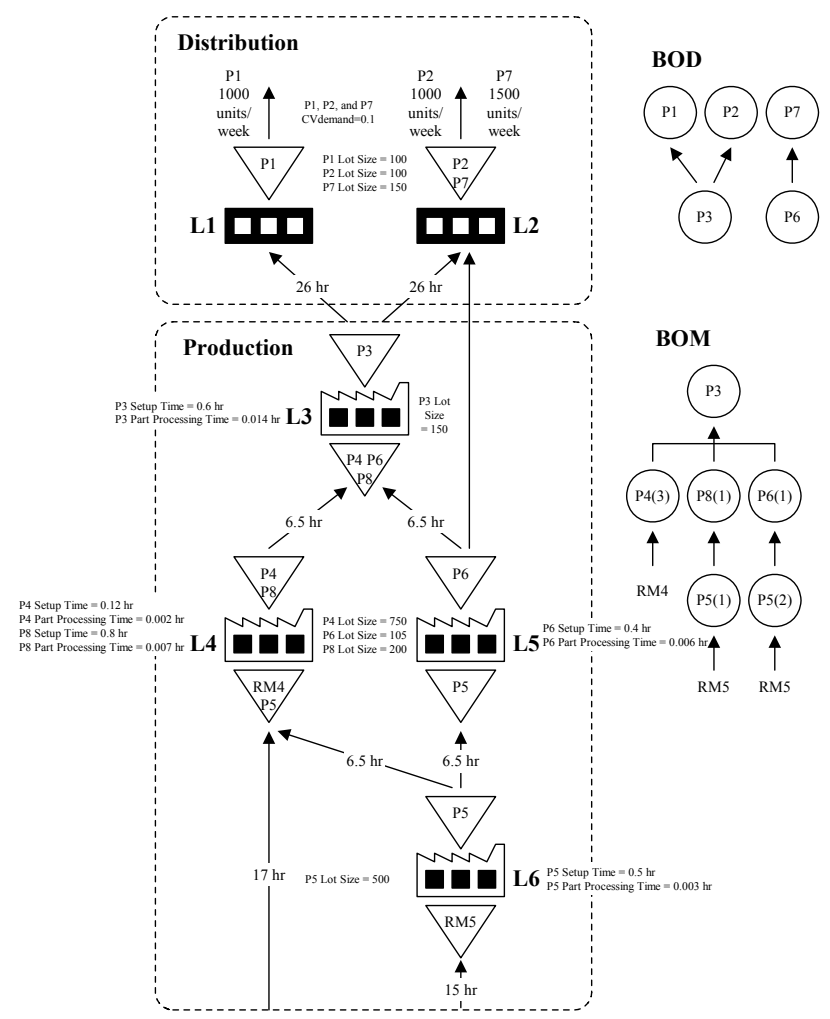

Figure 3. Configuration of Supply Chain Network

The most interesting result is that the Kanban system performed the best when the demand pattern was level and there were capacity constraints. This behavior was not observed without capacity constraints. As well, it is not intuitive since under the assumptions made, the main difference between the KBN and ROP strategies was the use of backorder information for ROP. It would usually be anticipated that more information should lead ROP to outperform KBN. However, further analysis showed that the lot interarrival time coefficients of variation, $c_{a}$, were lower when using KBN and therefore average queue lengths were shorter. The lot interarrival time variability is a function of the demand uncertainty, the way the replenishment strategy releases orders, and the upstream supply availability. It 
Table 4. Confidence Intervals for Pairwise Comparisons.

\begin{tabular}{|c|c|c|c|c|}
\hline $\begin{array}{c}\text { Capacity } \\
\text { Con- } \\
\text { straint }\end{array}$ & $\begin{array}{c}\text { Demand } \\
\text { Pattern }\end{array}$ & $\begin{array}{c}\text { ROP- } \\
\text { DRP/ } \\
\text { MRP }\end{array}$ & $\begin{array}{c}\text { KBN- } \\
\text { DRP/ } \\
\text { MRP }\end{array}$ & $\begin{array}{c}\text { KBN- } \\
\text { ROP }\end{array}$ \\
\hline \multirow{2}{*}{ No } & Level & $(-507$, & $(502$, & $(877$, \\
& & $-243)$ & $766)$ & $1142)$ \\
\cline { 2 - 5 } & Seasonal & $(152$, & $(1291$, & $(955$, \\
& & $518)$ & $1657)$ & $1322)$ \\
\hline Yes & Level & $(41$, & $(-300$, & $(-479$, \\
& & $317)$ & $-23)$ & $-203)$ \\
\cline { 2 - 5 } & Seasonal & $(210$, & $(664$, & $(19$, \\
& & $1079)$ & $1534)$ & $889)$ \\
\hline
\end{tabular}

was found that the use of backorder information actually caused ROP to overreact in situations where the variability was simply random over time, thus increasing order interarrival time variability and queue lengths.

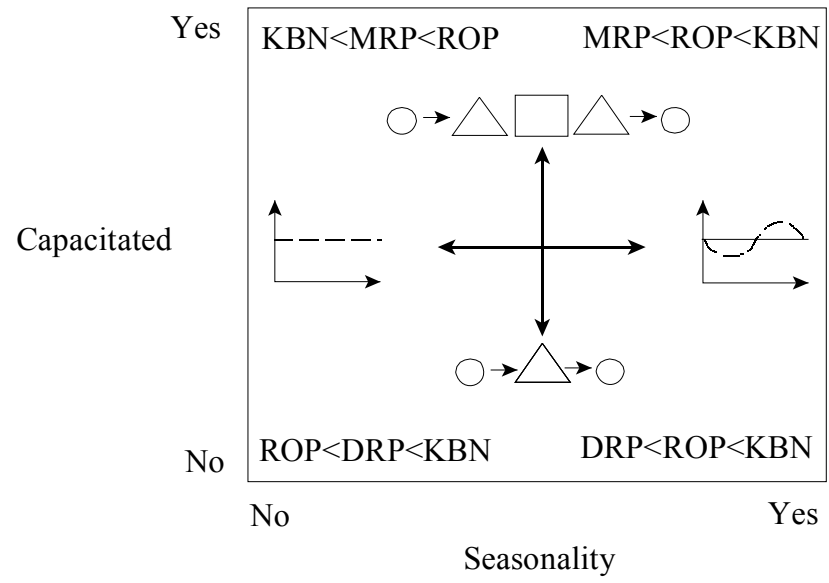

Figure 4. Replenishment Strategy Performance Ranking

\section{ACKNOWLEDGMENTS}

This research was supported in part by a grant from the National Science and Engineering Research Council (NSERC) of Canada.

\section{REFERENCES}

Enns, S.T., and S. Choi, 2002. Use of $G I / G / 1$ queuing approximations to set tactical parameters for the simulation of MRP systems, Proceedings of the 2002 Winter Simulation Conference, ed. Yücesan, E., Chen, C.-H., Snowdon, J.L. and Charnes, J. M., 1122-1129. Piscataway, New Jersey: IEEE.

Enns, S.T., and P. Suwanruji. 2003. A simulation test bed for production and supply chain modeling, Proceedings of the 2003 Winter Simulation Conference, ed. Chick, S., Sanchéz, P.J., Ferrin, S. and Morrice, D.J., 1174-1182. Piscataway, New Jersey: IEEE.
Enns, S. T., and L. Li. 2004. Optimal lot-sizing with capacity constraints and auto-correlated interarrival times. Proceedings of the 2004 Winter Simulation Conference, ed. Ingalls, R.G., Rossetti, M.D., Smith, J.S, and Peters, B.A., 1073-1078. Piscataway, New Jersey: IEEE.

Enns, S.T., and P. Suwanruji. 2005. Lot-sizing within capacity constrained manufacturing systems using timephased planning. Proceedings of the 2005 Winter Simulation Conference, ed. Kuhl, M.E., Steiger, N.M., Armstrong, F.B, and Joines, J.A., 1433-1440. Piscataway, New Jersey: IEEE.

Enns, S.T., and P. Zhu. 2005. Optimal lot-sizing in a twostage system with auto-correlated interarrivals. Proceedings of the 2005 Winter Simulation Conference, Kuhl, M.E., Steiger, ed. N.M., Armstrong, F.B, and Joines, J.A., 1705-1711. Piscataway, New Jersey: IEEE.

Goldratt, E.M, and J. Cox. 1984. The Goal: A process of ongoing improvement. Croton-on-Hudson, NY: North River Press.

Little, J.D.C., 1961. A proof of the queuing formula: $\mathrm{L}=\lambda \mathrm{W}$. Operations Research, 9, 383-387.

Suwanruji, P., and S.T. Enns. 2002. Information and logic requirements for replenishment systems. International Journal of Operations and Quantitative Management, 8 (3\&4), 149-164.

Suwanruji, P., and S.T. Enns. 2004. Evaluating the performance of supply chain simulations with trade-offs between multiple objectives. Proceedings of the 2004 Winter Simulation Conference, ed. Ingalls, R.G., Rossetti, M.D., Smith, J.S, and Peters, B.A., 1399-1403. Piscataway, New Jersey: IEEE.

Suwanruji, P., and S.T. Enns. 2006a. Comparison of supply chain replenishment strategies in a non-capacitated distribution system. International Journal of Risk Assessment and Management, Special Issue on Supply Chain Management, forthcoming.

Suwanruji, P. and S.T. Enns. 2006b, Evaluating the effects of capacity constraints and demand patterns on supply chain replenishment strategies. International Journal of Production Research, forthcoming.

Whitt, W. 1983. The Queueing Network Analyzer. The Bell Systems Technical Journal, 62 (9), 2779-2813.

\section{AUTHOR BIOGRAPHIES}

SILVANUS T. ENNS is an Associate Professor at the University of Calgary, Canada. His research interests lie in the development of algorithms to support enhanced MRP performance as well as various aspects of job shop, batch production and supply chain modeling and analysis. His email address is<enns@ucalgary.ca> . 
PATTITA SUWANRUJI develops scheduling and procurement systems for engineering and fabrication of equipment for the oil and gas industry. She has a $\mathrm{PhD}$ from the University of Calgary, an MEng in Industrial Engineering from Chulalongkorn University and a BEng in Chemical Engineering from Kasetsart University. Her email is $<$ psuwanru@shaw.ca $>$. 